\title{
PENGARUH LAMA PERIODE KERING DAN INTENSITAS CURAH HUJAN TERHADAP PENETASAN BELALANG KEMBARA (LOCUSTA MIGRATORIA MANILENSIS MEYEN)
}

\author{
Hamim Sudarsono ${ }^{1}$
}

\begin{abstract}
Effect of Dry Period and Rainfall Intensity on Emergence of the Migratory Locust (Locusta migratoria manilensis Meyen). Dry period and rainfall intensity were simulated experimentally to determine their effects on nymph emergence of the migratory locust (Locusta migratoria manilensis Meyen) (Orthoptera: Acrididae). The experiment was conducted in a factorial set up with two factors, i.e. dry periods (1, 2, 4, 8, and 12 week interval of watering) and rainfall intensity (80, 140, 200, and $260 \mathrm{~mm} / \mathrm{month})$. Locust nymphal emergence and time required to emerge after the watering were recorded and analyzed. Results of the experiment indicated that dry periods and rainfall levels affected nymphal emergence of the migratory locust. Interaction between dry periods and rainfall levels, however, were statistically not significant $(\mathrm{F}$-value $=$ 0,69 and P-value = 0,7526). Nymphal emergences of L. m. manilensis tended to be higher on soils that were watered less frequently. Similarly, locust emergences were also higher for the soil with lower rainfall intensity (received less amount of watering). At the $80 \mathrm{~mm} / \mathrm{month}$ rainfall level, 20 - 105,5 days period (egg incubation period) were required before the locust emergence. Incubation period of the eggs was significantly higher as the breeding media (soil) were watered less frequently. On the other hand, time required for the egg to emerge as nymphs was relatively similar regardless of the dry period levels. All eggs emerged $14-15,5$ days after watering.
\end{abstract}

Key words : Locusta migratoria manilensis Meyen, dry period, rainfall intensity, nymph emergence, egg incubation period

\section{PENDAHULUAN}

Belalang kembara (Locusta migratoria manilensis Meyen) (Orthoptera: Acrididae) merupakan salah satu hama penting tanaman pangan yang ledakan populasinya dapat menimbulkan kerugian dalam skala besar. Hama migran yang wilayah penyebarannya terdapat di seluruh Asia Tenggara ini merupakan sub-spesies dari belalang kembara Afrika (L. m. migratoroides) (Kalshoven, 1981). Khusus di Indonesia, L.m. manilensis merupakan satu-satunya spesies belalang yang mengalami fase transformasi dari sebanyak 51 spesies anggota famili Acrididae yang tercatat sebagai hama di Indonesia (Uvarov, 1977; Luong-Skovmand, 1999).

Beberapa tahun yang lalu sebagian wilayah pertanian di Indonesia secara serentak mengalami ledakan populasi hama belalang kembara dengan kerusakan utama terjadi pada tanaman padi dan serealia lainnya. Salah satu puncak wabah hama ini terjadi antara tahun 1998 hingga 2002 dengan wilayah kerusakan terluas di Provinsi Lampung. Selama bulan April hingga Mei 1998 ribuan hektar areal pertanian yang dilewati gerombolan belalang mengalami kerusakan total. Ribuan hektar tanaman padi menjelang panen dan tanaman jagung yang sedang berbunga hancur dalam waktu satu malam oleh hama yang sangat rakus ini (Kompas, 2 Mei 1998). Selain menyebabkan kerugian besar di Lampung, belalang kembara juga menyebabkan gagal panen di Bengkulu, Sumatera Selatan, Sulawesi Selatan, dan Kalimantan Tengah (Kompas, 4 Mei 1998). Kemudian hama ini juga dilaporkan mewabah di Kalimantan Barat, Sumba, Flores, dan Sulawesi (Lecoq, 1999).

Fenomena terjadinya ledakan populasi belalang kembara berskala besar diduga berkaitan erat dengan dua faktor utama, yaitu faktor biologi belalang kembara dan faktor lingkungan. Secara biologis, sebagai salah satu jenis belalang kembara, L.m.manilensis merupakan spesies polimorfik yang mengalami tiga transformasi populasi yaitu fase soliter (populasi rendah dan berperilaku individual), fase transisi (mulai berkelompok), dan fase gregarius (kelompok-kelompok belalang bergabung dan membentuk swarm yang menjadi sangat rakus dan merusak) (Ellis, 1953; Kalshoven, 1981). Dengan demikian, belalang kembara dapat berubah dari fase soliter menjadi fase gregarius jika kenaikan kepadatan populasi menyebabkan populasi belalang kembara fase soliter saling berdekatan dan beragregasi.

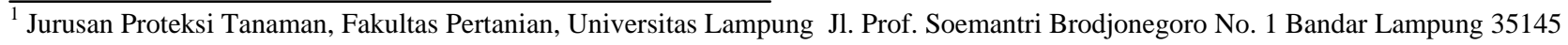


Agregasi ini selanjutnya menyebabkan berfungsinya feromon khusus yang memicu terjadinya proses gregarisasi (Loher, 1990).

Selain dipicu oleh tingkat kepadatan populasinya, proses transformasi polimorfik belalang kembara diduga juga dipengaruhi oleh pola curah hujan yang sesuai dengan perkembangan populasi hama belalang kembara. Perilaku hama ini di seluruh dunia diketahui berhubungan dengan pola iklim dan curah hujan. Belalang kembara dikenal sebagai serangga penting pada wilayah beriklim panas dan kering (semi-arid) (Scanlan et al., 2001). Di Australia yang $80 \%$ wilayahnya merupakan wilayah kering (arid dan semi-arid), curah hujan dilaporkan menjadi salah satu faktor pembatas pertumbuhan populasi hama belalang kembara (Hunter et al., 2001).

Sebelum terjadinya ledakan hebat belalang di Lampung pada tahun 1998, dilaporkan telah terjadi penyimpangan iklim secara nyata pada selama kurun waktu sepuluh tahun antara tahun 1989 hingga 1998. Selama kurun waktu sepuluh tahun tersebut, curah hujan yang tercatat di Provinsi Lampung adalah 33$234 \mathrm{~mm}$ (bulanan) dan $1.223 \mathrm{~mm}$ (tahunan). Kondisi ini lebih rendah daripada curah hujan rata-rata bulanan normal Lampung selama 30 tahun yang mencapai 96-275 mm dengan curah hujan tahunan 2.163 mm (Balai Peramalan Hama dan Penyakit Tanaman Pangan dan Hortikultura, 1999). Dengan demikian curah hujan selama 10 tahun dari tahun 1989 hingga 1998 tersebut adalah hampir separuh dari kondisi normal di Provinsi Lampung. Diduga, kondisi tersebut merupakan salah satu faktor yang sangat penting dalam memicu ledakan populasi belalang kembara di Lampung (Lecoq \& Sukirno, 1999).

Berdasarkan fenomena di atas maka perlu diselidiki secara empiris bagaimana pengaruh intensitas curah hujan dan lama periode kering terhadap perkembangan populasi belalang kembara. Sebagai tahap awal penyelidikan, percobaan ini dilaksanakan dalam bentuk simulasi intensitas curah hujan dan lama periode kering serta bertujuan menentukan tingkat penetasan telur belalang kembara dalam kondisi intensitas hujan dan periode kering yang berbeda-beda.

\section{METODE PENELITIAN}

Percobaan ini dilaksanakan di lahan dan fasilitas percobaan perkebunan tebu PT Gunung Madu
Plantation (GMP), Lampung Tengah. Percobaan disusun secara faktorial dalam rancangan kelompok dengan dua faktor. Faktor pertama adalah lama periode kering sejak peletakan telur hingga turunnya hujan yang pertama. Dalam faktor pertama ini diuji lima tingkat periode kering, yaitu: 1, 2, 4, 8, dan 12 minggu. Faktor kedua yang diselidiki adalah intensitas curah hujan yang dalam percobaan ini disimulasi dalam lima tingkat, yaitu: 80, 140, 200, dan $260 \mathrm{~mm} / \mathrm{bln}$. Simulasi intensitas curah hujan tersebut dilakukan dengan cara memberikan frekuensi dan interval penyiraman yang berbeda pada masingmasing pot tempat peletakan telur.

Sebelum percobaan dimulai, survei lokasi peletakan telur dilakukan di lahan pertanaman tebu untuk mengumpulkan kantung telur belalang kembara dan mengambil sampel tanah sebagai media penetasan telur. Telur belalang kembara juga diperoleh dari pemeliharaan belalang kembara dewasa dengan memberikan media tanah untuk peneluran. Untuk masing-masing satuan percobaan, tanah seberat $8 \mathrm{~kg}$ dimasukkan ke dalam pot (diameter $30 \mathrm{~cm}$; tinggi $50 \mathrm{~cm})$ sebanyak 80 buah $(5 \mathrm{x} 4$ perlakuan dengan 4 ulangan). Ke dalam setiap pot selanjutnya dimasukkan beberapa buah kantung telur belalang kembara dan kemudian dikurung dengan kurungan kasa. Kantung telur ini dibiarkan dalam kondisi kering (tanpa penyiraman) selama 1, 2, 4, 8, dan 12 minggu (sesuai dengan perlakuan). Setelah periode kering yang dibutuhkan tercapai, maka variasi penyiraman dilakukan untuk menyimulasi curah hujan yang berbeda, yaitu: 80, 140, 200, dan $260 \mathrm{~mm} / \mathrm{bln}$. Curah hujan tersebut dibagi secara merata selama 1 bulan sehingga terdapat interval penyiraman (frekuensi turun hujan) yang berbeda. Volume air yang diberikan untuk setiap kali penyiraman adalah $20 \mathrm{~mm}$ dengan interval dan frekuensi penyiraman seperti disajikan pada Tabel 1.

Masing-masing pot tanah yang telah ditutup selanjutnya diletakkan di lapangan rumput dan disusun dalam kelompok. Pengamatan terhadap jumlah telur yang menetas (jumlah nimfa yang muncul) serta lama hari yang diperlukan untuk menetas dilakukan setiap hari. Data yang diperoleh dianalisis dengan sidik ragam (analysis of variance) dan dilanjutkan dengan pembandingan nilai tengah (SAS Institute, 1988). 
Tabel 1. Interval penyiraman dan frekuensi penyiraman yang diterapkan pada masing-masing curah hujan yang disimulasi

\begin{tabular}{ccc}
\hline Curah Hujan yang Disimulasi & $\begin{array}{c}\text { Interval } \\
\text { Penyiraman }\end{array}$ & Frekuensi Penyiraman per bulan \\
\hline $80 \mathrm{~mm} / \mathrm{bln}$ & 7 hari & $4 \mathrm{x}$ \\
$140 \mathrm{~mm} / \mathrm{bln}$ & 4 hari & $7 \mathrm{x}$ \\
$200 \mathrm{~mm} / \mathrm{bln}$ & 3 hari & $10 \mathrm{x}$ \\
$260 \mathrm{~mm} / \mathrm{bln}$ & 2 hari & $13 \mathrm{x}$ \\
\hline
\end{tabular}

Tabel 2. Rerata persentase penetasan telur belalang kembara pada beberapa tingkat curah hujan dengan periode kering yang berbeda-beda

\begin{tabular}{lccccc}
\hline \multirow{2}{*}{ Periode Kering } & \multicolumn{4}{c}{ \% Penetasan Telur Belalang pada Curah Hujan } & \multirow{2}{*}{ Rerata } \\
\cline { 2 - 5 } & $80 \mathrm{~mm}$ & $140 \mathrm{~mm}$ & $200 \mathrm{~mm}$ & $260 \mathrm{~mm}$ & \\
\hline 1 Minggu & 78,57 & 66,67 & 72,40 & 13,33 & $57,74 \mathrm{~b}$ \\
2 Minggu & 24,79 & 31,16 & 33,33 & 21,84 & $27,78 \mathrm{a}$ \\
4 Minggu & 53,84 & 84,88 & 70,93 & 45,74 & $63,85 \mathrm{~b}$ \\
8 Minggu & 36,47 & 23,08 & 24,82 & 0,00 & $21,09 \mathrm{a}$ \\
12 Minggu & 51,03 & 32,18 & 0,00 & 0,00 & $20,80 \mathrm{a}$ \\
\hline Rerata & $48,94 \mathrm{~A}$ & $47,59 \mathrm{~A}$ & $40,30 \mathrm{AB}$ & $16,18 \mathrm{~B}$ & \\
\hline
\end{tabular}

Keterangan : Nilai rerata dalam kolom atau baris yang sama yang diikuti oleh tanda huruf berbeda menunjukkan hasil pembandingan nilai tengah berbeda nyata.

\section{HASIL DAN PEMBAHASAN}

Hasil percobaan menunjukkan bahwa simulasi lama periode kering dan intensitas curah hujan secara terpisah masing-masing berpengaruh terhadap persentase penetasan telur belalang kembara. Namun demikian, interaksi antara faktor curah hujan dan lama periode kering tersebut tidak berpengaruh secara nyata (nilai-F $=0,69$ dan nilai-P $=0,7526$ ) terhadap persentase peneluran belalang kembara. Secara umum persentase penetasan telur belalang kembara semakin rendah jika intensitas curah hujan semakin tinggi. Pada simulasi curah hujan $80 \mathrm{~mm}$, persentase penetasan telur tercatat sebesar $48,94 \%$ dan secara tidak signifikan menurun menjadi $40,30 \%$ pada intensitas curah hujan $200 \mathrm{~mm}$. Selanjutnya persentase penetasan telur menjadi lebih rendah (16,18\%) pada intensitas curah hujan $260 \mathrm{~mm}$. Sementara itu, analisis data berdasarkan lama periode kering menunjukkan bahwa penetasan telur belalang kembara terjadi pada semua periode kering yang dicoba, dari 1 minggu hingga 4 minggu interval penyiraman. Secara umum diperoleh persentase penetasan telur tertinggi pada periode interval selama 4 minggu dengan tingkat penetasan telur sebesar 63,85\%. Dengan demikian dari percobaan ini dapat disimpulkan bahwa persentase penetasan telur belalang kembara pada periode kering selama $1-4$ minggu relatif sama. Persentase penetasan telur tercatat secara signifikan lebih rendah pada periode kering 8-12 minggu, yaitu sekitar 20\% (Tabel 2).

Sebagai analisis lanjutan, pada intensitas curah hujan $80 \mathrm{~mm} /$ bulan diperoleh bahwa periode inkubasi telur belalang kembara semakin panjang pada kondisi yang semakin kering yang dalam percobaan ini disimulasi dengan interval penyiraman yang semakin lama. Pada periode kering 1 minggu, waktu inkubasi yang diperlukan sebelum telur belalang kembara menetas adalah 21 hari. Waktu inkubasi ini secara signifikan semakin panjang seiring dengan semakin panjangnya interval penyiraman. Periode inkubasi telur belalang kembara terpanjang yang diperoleh adalah 105,5 hari, yaitu pada periode kering 12 minggu (Tabel 3). Jika dihitung sejak terjadinya hujan 
Tabel 3. Periode inkubasi dan waktu penetasan telur belalang kembara pada beberapa tingkat periode kering (dengan curah hujan $80 \mathrm{~mm} / \mathrm{bulan}$ )

\begin{tabular}{ccc}
\hline Periode Kering & Periode Inkubasi Telur (hari) & $\begin{array}{c}\text { Waktu untuk Menetas } \\
\text { setelah Terjadinya Hujan (Hari) }\end{array}$ \\
\hline 1 minggu & $21,0 \mathrm{a}$ & 14,67 \\
2 minggu & $26,0 \mathrm{a}$ & 12,00 \\
4 minggu & $44,0 \mathrm{~b}$ & 14,00 \\
8 minggu & $75,5 \mathrm{c}$ & 15,50 \\
12 minggu & $105,5 \mathrm{~d}$ & 15,50 \\
\hline Nilai $-\mathrm{F}$ & 87,234 (sangat nyata) & 2,306 (tidak nyata) \\
\hline
\end{tabular}

Keterangan : Nilai rerata dalam baris yang sama yang diikuti oleh tanda huruf berbeda menunjukkan hasil pembandingan nilai tengah berbeda nyata.

atau penyiraman, ternyata waktu yang diperlukan telur untuk menetas pada semua perlakuan periode kering relatif sama, yaitu 14,00 - 15,50 hari. Dari hasil ini maka dapat dikonfirmasi mengapa ledakan populasi belalang kembara biasanya terjadi setelah di suatu wilayah terjadi periode kering yang panjang. Dua hal yang menyebabkan terjadinya fenomena ini kemungkinan adalah periode inkubasi telur dan waktu penetasan setelah terjadinya hujan. Masa periode inkubasi telur yang kisarannya cukup luas (21 - 105,5 hari) menyebabkan telur belalang kembara akan bertahan di dalam tanah selama di hamparan tersebut belum turun hujan. Selanjutnya, setelah turun hujan dengan intensitas yang sesuai maka seluruh kelompok telur belalang kembara yang terpendam di dalam tanah akan menetas dalam waktu 14,00 - 15,50 hari.

Hasil percobaan di atas mungkin dapat menjelaskan mengapa terjadinya ekplosi belalang kembara di suatu wilayah biasanya mengikuti terjadinya musim kemarau sangat panjang. Salah satu alasannya adalah terjadinya akumulasi penetasan atau penetasan serentak dari telur belalang kembara. Beberapa hasil penelitian menunjukkan bahwa waktu penetasan telur (yang diletakkan secara masal di dalam tanah) merupakan titik awal dari ledakan populasi belalang kembara (Lecoq \& Sukirno, 1999). Waktu peletakan telur secara masal sangat dipengaruhi oleh faktor cuaca, yaitu kondisi kemarau panjang yang juga berhubungan dengan kondisi tanah. Kondisi seperti ini menurut Lecoq \& Sukirno (1999) terjadi di Sumatera bagian selatan pada tahun 1998 dengan kemungkinan penyebab utamanya antara lain terjadinya peningkatan populasi melalui pembiakan serta terjadinya konsentrasi hamparan peneluran melalui berkurangnya lahan yang tertutup tumbuhtumbuhan. Secara hipotetis, dinamika terjadinya ledakan populasi belalang kembara oleh Lecoq dan Sukirno (1999) diilustrasikan seperti pada Gambar 1.

Hasil percobaan ini menunjukkan bahwa telur belalang yang sudah berada di dalam tanah dalam waktu 21 - 105 hari akan menetas secara serentak 14,7 - 15,5 hari setelah terjadinya hujan yang sesuai untuk kondisi penetasan telur belalang kembara. Meskipun demikian, dari hasil percobaan ini belum dapat disimpulkan berapa kadar curah hujan yang sesuai untuk memicu terjadinya penetasan belalang kembara. Sebagaimana dilaporkan oleh Hunter et al. (2001), curah hujan merupakan faktor pembatas penting dalam dinamika populasi belalang kembara, bukan hanya dalam intensitasnya tetapi juga dalam variasi besaran curah hujannya. Ketika lama periode kering dan tingkat curah hujan sesuai sebagai kondisi optimal penetasan telur belalang kembara maka penetasan masal diduga dapat terjadi. Selanjutnya, dengan didukung oleh faktor-faktor alam lainnya, misalnya ketidakmampuan musuh alami (predator, parasit, dan patogen) dalam mengendalikan populasi, maka eksplosi populasi besar-besaran dapat terjadi di suatu wilayah. Jika hasil pengamatan lama periode inkubasi dan waktu terjadinya penetasan telur belalang kembara dari percobaan ini dihubungkan dengan ilustrasi hipotetis sebagaimana yang dikemukakan oleh Lecoq \& Sukirno (1999) maka proses terjadinya ledakan populasi hama belalang kembara dapat dirangkum sebagaimana pada Gambar 2. 


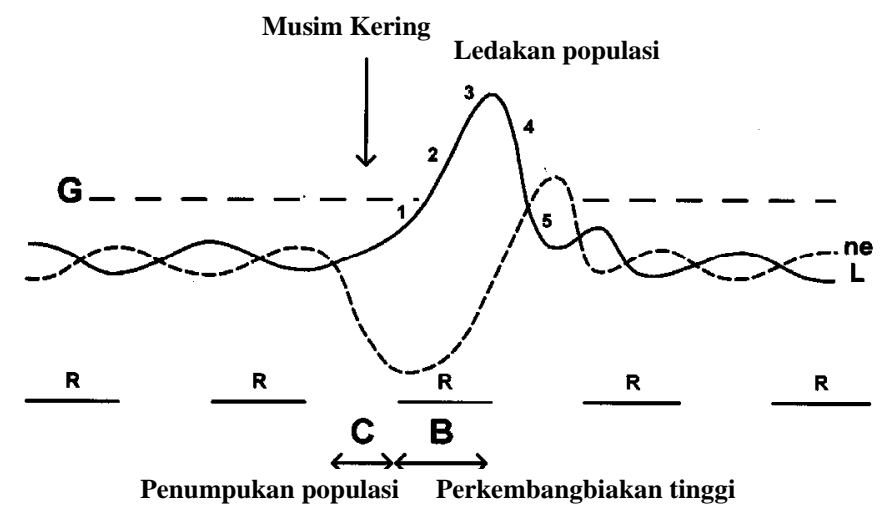

Gambar 1. Dinamika populasi belalang kembara di Sumatera bagian selatan dan pengaruh musuh alami terhadap pengendalian populasi (hipotetis). B, kemungkinan peningkatan populasi melalui perkembangbiakan; C, kemungkinan terjadinya pemadatan populasi akibat berkurangnya areal yang tertutup tanaman (karena pembukaan lahan); G, ambang gregarisasi (2000 belalang dewasa per ha); L, populasi belalang kembara; ne, populasi musuh alami; R, musim hujan; 1-5 generasi bersinambungan (3 pada musim hujan dan 2 pada musim kemarau) (Lecoq \& Sukirno, 1999).

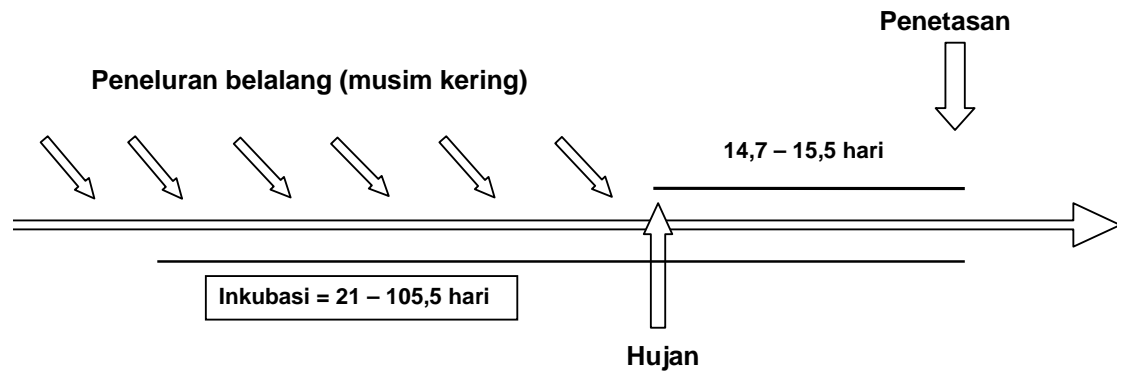

Gambar 2. Proses terjadinya eksplosi hama belalang kembara setelah periode kering panjang yang menyebabkan terjadinya akumulasi telur di dalam tanah dan menetas secara serentak 14,7 - 15,5 hari setelah terjadinya curah hujan yang sesuai.

\section{SIMPULAN}

Simulasi lama periode kering dan intensitas curah hujan secara terpisah masing-masing berpengaruh terhadap persentase peneluran belalang kembara. Namun demikian, interaksi antara faktor curah hujan dan lama periode kering tersebut tidak berpengaruh secara nyata (nilai- $\mathrm{F}=0,69$ dan nilai-P $=$ 0,7526) terhadap persentase peneluran belalang kembara. Jumlah telur yang menetas cenderung lebih tinggi pada pot tanah yang kering (mendapat frekuensi penyiraman rendah). Demikian juga, persentase penetasan telur belalang kembara juga semakin tinggi pada tanah dengan intensitas curah hujan rendah. 
Pada intensitas curah hujan $80 \mathrm{~mm} / \mathrm{bulan}$, periode inkubasi telur belalang kembara 21-105,5 hari tergantung dari lama periode keringnya (semakin lama periode kering, inkubasi semakin panjang). Namun demikian, waktu yang diperlukan telur untuk menetas setelah terjadinya hujan pada semua perlakuan periode kering konsisten, yaitu 14,00 - 15,50 hari. Telur belalang kembara akan bertahan di dalam tanah selama di hamparan dan akan menetas sekitar dua minggu setelah terjadinya hujan dengan intensitas yang sesuai. Data ini menjelaskan fenomena alam mengapa ledakan populasi belalang kembara biasanya terjadi setelah kemarau yang panjang.

\section{SANWACANA}

Penulis mengucapkan terima kasih kepada rekan Prof. Dr. Rosma Hasibuan (Unila) dan Dr. Damayanti Buchorie (IPB) yang telah bekerjasama dengan penulis dalam rangkaian penelitian bologi dan dinamika populasi belalang kembara di Lampung. Ucapan terima kasih juga disampaikan kepada para mahasiswa bimbingan penulis yang telah terlibat dalam sebagian dari penelitian ini.

\section{DAFTAR PUSTAKA}

Balai Peramalan Hama dan Penyakit Tanaman Pangan dan Hortikultura. 1999. Pengembangan Model Peramalan Belalang Kembara pada Tanaman Pangan di Lampung dengan Pemanfaatan Sistem Informasi Geografis.

Ellis, P.E. 1953. Social agregation and gregarious behaviour in hoppers of Locusta migratoria migratoriodes R. \& F.. Behaviour 5 : 225-260.

Hunter, D.M., P.W. Walker, \& R.I. Elder. 2001. Adaptations of locusts and grasshoppers to the low and variable rainfall of Australia J. of Orthoptera Res. 10 (2): 347-351.
Kalshoven, L.G.E. 1981. The Pests of Crops in Indonesia. PT Ichtiar Baru-Van Hoeve, Jakarta $701 \mathrm{hlm}$.

Kompas. 1998. Serangan belalang mengganas. Harian Kompas, 2 Mei 1999.

Kompas. 1998. Belalang Serang Lima Propinsi. Harian Kompas, 4 Mei 1999.

Lecoq, M. 1999. Outbreaks of the oriental migratory locust in Indonesia. Unpublished paper presented in "Seminar for technology transfer of locust survey and control”. Lampung, 12-16 July 1999.

Lecoq, M. \& Sukirno. 1999. Drought and an exceptional outbreak of the oriental migratory locust, Locusta migratoria manilensis (meyen 1835) in Indonesia (Orthoptera: Acrididae). J. Orthoptera Res. 8: 153 - 161.

Loher, W. 1990. Pheromones and phase transformation in locusts. In Chapman \& Joern eds.), Biology of Grashoppers. John Wiley \& Sons. New York. Pp. 337-356.

Luong-Skovmand. 1999. Biology of the oriental migratory locust. Unpublished paper presented in "Seminar for technology transfer of locust survey and control”. Lampung, 12-16 July 1999. $43 \mathrm{pp}$.

Scanlan, J.C., W.W. Grant, D.M. Hunter, \& R.J. Milner. 2001. Habitat and environmental factors influencing the control of migratory locusts (Locusta migratoria) with an entomopathogenic fungus (Metarhizium anisopliae). Ecological Modelling 136: 223236.

Uvarov, B. P. 1977. Grasshoppers and Locusts. A Handbook of General Acridology. COPR, London. 